\title{
Rotational Acceleration Closed Head Flexion Trauma Generates More Extensive Diffuse Brain Injury than Extension Trauma
}

\author{
Ulrika Krave, Mohamed Al-Olama, ${ }^{2,3}$ and Hans-Arne Hansson ${ }^{2}$
}

\begin{abstract}
Our aim was to investigate if seemingly identical head and neck trauma would generate differing types of brain damage. We experimentally evaluated induced brain injuries immediately after trauma exposure, and at 1 week post-injury. Anesthetized rabbits were exposed once to a sagittal rotational acceleration head and neck injury at either a high or a low load level, using either flexion or extension. A high-load extension trauma induced scattered meningeal petechial hemorrhages and no deaths, in contrast to a flexion trauma of the same level, which resulted in extensive parenchymal and meningeal hemorrhages, and all animals succumbed immediately. A low-level flexion trauma induced scattered meningeal petechiae, but no gross damage, while extension at the same force generated no macroscopically visible acute brain injury. Immunohistochemical investigations carried out at 7 days disclosed that a low-level flexion trauma, as well as both low- and high-level extension exposures, all induced diffuse brain injuries in the cerebral cortex and white matter, corpus callosum, hippocampus, brainstem, and cerebellum, as revealed by abnormal distribution of neurofilaments, a prevalence of $\beta$-amyloid precursor protein, and astrogliosis. The diffuse brain injury seen after a low-level flexion trauma was equal to or more extensive than that seen after a high-level extension trauma. A low-level extension trauma induced only minor histopathological abnormalities. We conclude that a sagittal rotational acceleration trauma of the head and neck induced diffuse brain injury, and that flexion caused more extensive damage than extension at the same applied load.
\end{abstract}

Key words: astrocytosis; $\beta$-amyloid precursor protein; diffuse axonal injury; mild traumatic brain injury; neurofilaments

\section{Introduction}

W ORLDWIDE, TRAUMATIC BRAIN INJURIES (TBI) annually take a great toll, causing impairment and death, as well as long-term sickness and disability due to persistent sequelae (Faul et al., 2010; Greenberg, 2010; Langlois et al., 2006; Ommaya et al., 2002; Reilly and Bullock, 2005). Brain injuries are traditionally classified as focal or diffuse, the latter being by far most common. Concussion or mild traumatic brain injury is diffuse, and may vary from causing minimal symptoms, to severe impairment and even death. It is difficult to assess how seemingly similar types of traumata could generate such a wide range of consequences. Victims with diffuse brain injury (DBI) have frequently been exposed to a combination of rotational and translational loading, causing either flexion or extension of the head and neck, but with no resulting brain contusions, hemorrhages, or bone fractures (Blumbergs et al., 2008; Greenberg, 2010; Oehmichen et al., 2005; Reilly and Bullock, 2005). The brain may move and turn with a closed head trauma, but the precise mechanisms generating the injury are complex (Bayly et al., 2006; Gosch et al., 1970; Greenberg, 2010; Leestma, 2008; Oehmichen et al., 2005; Pudenz and Sheldon, 1946; Sabet et al., 2008). The specific nature and distribution of the DBI seen after closed head trauma depends on the type of load applied, its severity, and the position at which it is applied (LaPlaca and Prado, 2010; Leestma, 2008; Oehmichen et al., 2005; Reilly and Bullock, 2005). Brain tissue is heterogeneous and anisotropic, and as a result identical loads may generate different injury patterns, depending on their direction. Animal models of TBI are thought to mimic some aspects of human DBI (Cernak, 2005; Kilbourne et al., 2009; Morales et al., 2005). Rotation, often in

\footnotetext{
${ }^{1}$ Division of Vehicle Safety, Applied Mechanics, Chalmers University of Technology, Göteborg, Sweden.

${ }^{2}$ Institute of Biomedicine, Sahlgrenska Academy, University of Gothenburg, Göteborg, Sweden.

${ }^{3}$ Department of Neurosurgery, Sahlgrenska University Hospital, Göteborg, Sweden.
} 
combination with translation, in the sagittal plane frequently occurs in human trauma (e.g., falls and motor vehicle accidents). The focus of most TBI studies has been on frontal impacts to the head, while occipital impacts have received less attention, and the injury patterns seen with TBI differ with the direction of the applied force (Greenberg, 2010; Leestma, 2008; Oehmichen et al., 2005).

We have reported that dynamic, transient pressures are generated in the brain parenchyma during sagittal rotational closed head trauma at both flexion and extension (Krave et al., 2005 , 2010). A sagittal rotational acceleration pulse with a duration of $1 \mathrm{msec}$ results in the generation of dynamic pressures in the brain parenchyma lasting as long as $25 \mathrm{msec}$. Further, the direction of the load strongly influences the pressure pattern. Predominantly negative dynamic pressures were recorded with a flexion trauma, in contrast to the consecutive positive and negative pressure peaks seen with extension trauma. The magnitudes of the negative amplitudes were larger and lasted longer with flexion trauma compared to extension trauma of the same degree (Krave et al., 2010). These differences in the pressure patterns recorded in the brain parenchyma, and the paucity of macroscopically visible gross brain damage (except that seen after high-level flexion trauma), induced us to examine the exposed brains histopathologically. The aim of the present study was to immunohistochemically investigate brains and spinal cords $30 \mathrm{~min}$ after trauma, and again after 1 week, for injuries at the cellular level, and to elucidate any correlation between the histopathological patterns seen and the direction and level of the trauma applied.

\section{Methods}

\section{Animals and surgical preparation}

Female New Zealand albino rabbits $(2.3-3 \mathrm{~kg})$ were anesthetized by intramuscular injections of Dormicum ${ }^{\circledR}$ (Roche Diagnostics GmbH, Mannheim, Germany) and Hypnorm ${ }^{\circledR}$ (Janssen Pharmaceutica, Beerse, Belgium), prior to the surgery required to attach a helmet to the skull, and the subsequent exposure to trauma (Krave et al., 2005). Briefly, a midline incision was made through the skin and periosteum on the skull vault, and the calvarial bone was freed from ad- herent tissue. A helmet made of glass-fiber reinforced epoxy plastic and shaped to match the contours of the exposed skull was secured to the bone with glue (Super-Bond C \& B ${ }^{\circledR}$; Sun Medical Co., Shiga, Japan). The helmet provided a firm attachment between the rabbit's head and a bar that rotated around a horizontal axis. The center of rotation was approximated to the center of gravity of the head, inferior to the brain and close to the pituitary stalk (Gutierrez et al., 2001). The rotating bar, when hit by a piston driven by compressed air, forced the head into a sagittal rotational acceleration motion. The angular rotation was set to $22^{\circ}$, with the rabbit's head and neck in the position the animal is in when looking forward at the ground a few meters ahead. The sagittal movement of the head and neck at flexion, as well as at extension, was thus within the physiologic range. All animals were relaxed prior to trauma exposure. The magnitude of the acceleration was recorded with an accelerometer (7264B-2000TZ; Endevco Corp., San Juan Capistrano, CA) attached to the rotating bar.

These experiments were approved by the Regional Animal Experiments Ethical Committee, and were performed in accordance with local, national, and European Union (EU) guidelines for animal experiments (EU 86/609/EEC). All efforts were made to minimize the number of animals used and their suffering.

\section{Test procedure}

Each anesthetized rabbit was exposed once to a sagittal plane head and neck rotational acceleration, either as a flexion or an extension. Two levels of acceleration were used: a low level at $97 \mathrm{krad} / \mathrm{sec}^{2}$ (standard deviation $13.9 \mathrm{krad} / \mathrm{sec}^{2}$ ), and a high level at $193 \mathrm{krad} / \mathrm{sec}^{2}$ (standard deviation $10.5 \mathrm{krad} /$ $\mathrm{sec}^{2}$; Krave et al., 2010). The previously used experimental setup (Gutierrez et al., 2001) was modified to avoid brain contusions and parenchymal hemorrhages (Krave et al., 2005). All animals remained anesthetized during trauma exposure, and for at least $10 \mathrm{~min}$ thereafter, in agreement with the granted permits. It was thus possible to check post-traumatic awareness, but not wakefulness.

Two different groups of animals were investigated in the present study. The first group consisted of 15 animals, which were kept anesthetized and then sacrificed $30 \mathrm{~min}$ after trauma (Table 1). The rabbits were fixed by transcardial per-

Table 1. Macroscopically Visible Changes Seen 30 Min After Exposure to a Rotational Acceleration Impulse

\begin{tabular}{|c|c|c|c|c|c|}
\hline $\begin{array}{l}\text { Exposure } \\
\text { condition }\end{array}$ & $\begin{array}{l}\text { Survival rate } \\
\text { after exposure }\end{array}$ & $\begin{array}{l}\text { Subarachnoid } \\
\text { hemorrhage }\end{array}$ & $\begin{array}{l}\text { Olfactory bulb } \\
\text { hemorrhage }\end{array}$ & $\begin{array}{c}\text { Subarachnoid } \\
\text { hemorrhage } \\
\text { at the interface of } \\
\text { the medulla/C1 }\end{array}$ & $\begin{array}{l}\text { Parenchymal } \\
\text { hemorrhage }\end{array}$ \\
\hline Sham exposed & $3 / 3(100 \%)$ & None & No & No & None \\
\hline $\begin{array}{l}\text { Low-level } \\
\text { extension }\end{array}$ & $3 / 3(100 \%)$ & None & No & No & None \\
\hline $\begin{array}{l}\text { High-level } \\
\text { extension }\end{array}$ & $3 / 3(100 \%)$ & $\begin{array}{l}\text { Occasionally scattered } \\
\text { on basal brain }\end{array}$ & No & No & None \\
\hline $\begin{array}{l}\text { Low-level } \\
\text { flexion }\end{array}$ & $3 / 3(100 \%)$ & $\begin{array}{l}\text { Scattered on hemispheres } \\
\text { and basal brain }\end{array}$ & $\begin{array}{l}1-3 \text { petechiae } \\
\text { per bulb }\end{array}$ & $\begin{array}{l}\text { Scattered petechiae } \\
\text { on dorsal surface }\end{array}$ & None \\
\hline $\begin{array}{l}\text { High-level } \\
\text { flexion }\end{array}$ & $0 / 3(0 \%)$ & Diffuse and extensive & $\begin{array}{c}\text { Meningeal and } \\
\text { parenchyma } \\
\text { hemorrhages }\end{array}$ & $\begin{array}{l}\text { Extensive hemorrhages, } \\
\text { dorsal and ventral }\end{array}$ & $\begin{array}{l}\text { Multiple throughout } \\
\text { the brain }\end{array}$ \\
\hline
\end{tabular}

All brains were carefully removed, inspected, and dissected $30 \mathrm{~min}$ after the exposure of an anesthetized animal. 
Table 2. Prevalence of NF-H-Immunoreactive Neurons in the Brains at 1 Week

\begin{tabular}{|c|c|c|c|c|c|c|}
\hline Exposure condition & $\begin{array}{l}\text { Parietal cortex, } \\
\text { layers III } \\
\text { and } V\end{array}$ & $\begin{array}{l}\text { Cerebral white } \\
\text { matter, abnormal } \\
\text { axons }\end{array}$ & $\begin{array}{l}\text { Hippocampus, } \\
\text { pyramidal } \\
\text { nerve cells }\end{array}$ & $\begin{array}{l}\text { Olfactory bulb, } \\
\text { mitral cells }\end{array}$ & $\begin{array}{l}\text { Cerebellum, } \\
\text { parallel fibers }\end{array}$ & $\begin{array}{l}\text { Cerebellum, } \\
\text { climbing fibers }\end{array}$ \\
\hline Unexposed controls & - & - & - & - & - & - \\
\hline Low-level extension & $(+)$ & $(+)$ & + & + & + & - \\
\hline High-level extension & + & + & + & ++ & $+(+)$ & + \\
\hline Low-level flexion & ++ & ++ & ++ & ++ & +++ & +++ \\
\hline
\end{tabular}

The distribution of NF-H in axons was investigated immunohistochemically 1 week after exposure to trauma, and compared to that seen in unexposed controls. All rabbits exposed to a high-level flexion succumbed to the injury.

- , unexposed or not diverging from unexposed; $(+)$, slightly increased prevalence, but not in all animals; + , slightly increased; $+(+)$, moderately increased, but not in all animals; ++ moderately increased; +++ , strongly increased in all animals as compared to unexposed animals; NF-H, heavy subunit of neurofilament.

fusion of buffered formalin in phosphate-buffered saline (PBS), after an initial rinse with PBS containing heparin (500 IE/L). The brain and upper spinal cord was then removed for macroscopic visual inspection to assess the prevalence of acute gross damage (i.e., hemorrhages, contusions, and deformations of the brain and cervical spinal cord). A second group of rabbits survived 7 days after a single exposure, and comprised 16 animals, all of which were analyzed immunohistochemically, and of those 4 were exposed once to a low-level extension, 4 to a high-level extension, 4 to a lowlevel flexion, and 4 were sham exposed (Tables 2, 3, and 4). Further, normal, unexposed rabbits were investigated for comparison.

\section{Tissue preparation}

After being fixed by perfusion $30 \mathrm{~min}$ after trauma, the rabbit brains used for the acute examinations were dissected, inspected, photographed, and sectioned coronally. For the brains used for immunohistochemical investigations at 1 week after the exposure, after transcardial fixation and dissection, they were immersed in buffered formalin for at least 1 day, and then transferred for cold storage in $20 \%$ sucrose and $0.05 \%$ sodium azide in PBS (Gutierrez et al., 2001; Zhu et al., $2003,2005)$. Selected specimens were prepared from coronal slices of the frontal, parietal, and occipital lobes, as well as of basal nuclei and the hippocampus (Shek et al., 1986). Additional slices were prepared from the cerebellum and the brainstem. The latter was divided into three main portions: midbrain and pons; medulla oblongata; and cervical spinal cord (Shek et al., 1986).

\section{Antibodies}

A monoclonal antibody against the heavy subunit of neurofilaments (NF-H) was purchased from Novocastra (dilution 1:100; Leica Microsystems, Bannockburn, IL), and a monoclonal antibody against glial fibrillary acidic protein (GFAP) was purchased from Sigma-Aldrich (clone GA5, dilution 1:1000; St. Louis, MO). A goat polyclonal antibody against $\beta$-amyloid precursor protein $(\beta$-APP) was from Chemicon International (dilution 1:1000; Temecula, CA).

\section{Immunohistochemistry}

Free-floating sections, prepared at a nominal thickness of $25 \mu \mathrm{m}$ with the aid of a cryostat microtome, were used for immunohistochemistry (Gutierrez et al., 2001; Zhu et al., 2003, 2005). The sections were initially immersed in TRISbuffered saline (TBS), containing 5\% normal horse serum to block non-specific binding, and then incubated in the cold overnight in the specific primary antibody, diluted in $2 \%$ bovine serum albumin in TBS containing 0.05\% Tween- 20 . The next day the free-floating sections were rinsed and incubated in a diluted biotinylated secondary antibody. After additional rinsing the sections were incubated in a complex of avidin, biotin, and horseradish peroxidase. Eventually the sections were developed in diaminobenzidine solution, allowed to stick to glass slides, and mounted. All procedures were carried out with gentle shaking. For reference, additional sections were processed in parallel, but with the primary antibody omitted. To enable comparison, sections from exposed and unexposed animals were positioned on the same

Table 3. Prevalence of $\beta$-APP-Expressing Neurons in Rabbit Brains after 1 Week

\begin{tabular}{lccccccc}
\hline & $\begin{array}{c}\text { Parietal } \\
\text { cortex, } \\
\text { layer III }\end{array}$ & $\begin{array}{c}\text { Parietal } \\
\text { cortex, } \\
\text { layer }\end{array}$ & $\begin{array}{c}\text { Cerebral white } \\
\text { matter axons }\end{array}$ & $\begin{array}{c}\text { Hippocampus } \\
\text { (CA1) }\end{array}$ & $\begin{array}{c}\text { Hippocampus } \\
\text { (CA3) }\end{array}$ & $\begin{array}{c}\text { Cerebellum, } \\
\text { Purkinje } \\
\text { nerve cells }\end{array}$ & $\begin{array}{c}\text { Axons } \\
\text { in the brainstem }\end{array}$ \\
\hline Unexposed controls & - & - & - & - & - & - & - \\
Low-level extension & - & + & $(+)$ & $(+)$ & + & + & $+(+)$ \\
High-level extension & $(+)$ & + & + & + & + & + \\
Low-level flexion & + & ++ & ++ & ++ & ++ & ++ \\
\hline
\end{tabular}

Immunohistochemical visualization of $\beta$-APP in rabbit brains at 1 week after exposure. All rabbits exposed to a high-level flexion succumbed to the injury.

- , no $\beta$-APP immunoreactivity; $(+)$, scattered $\beta$-APP-positive neurons, but not in all animals; + , scattered $\beta$-APP positive neurons; $+(+)$, moderate $\beta$-APP-positive neurons, but not in all animals; ++ , moderate prevalence of $\beta$-APP immunoreactivity in all animals compared to unexposed animals; $\beta$-APP, $\beta$-amyloid precursor protein. 
Table 4. Prevalence of Hypertrophic GFAP-Positive Astrocytes 1 Week after Exposure

\begin{tabular}{lccccccc}
\hline Exposure condition & $\begin{array}{c}\text { Parietal cortex, } \\
\text { layer II }\end{array}$ & $\begin{array}{c}\text { Parietal cortex, } \\
\text { layers V-VI }\end{array}$ & Hippocampus & $\begin{array}{c}\text { Columna } \\
\text { fornici }\end{array}$ & $\begin{array}{c}\text { Dentate } \\
\text { gyrus }\end{array}$ & $\begin{array}{c}\text { Cerebellum, } \\
\text { molecular layer }\end{array}$ & $\begin{array}{c}\text { Cerebellum, } \\
\text { granular layer }\end{array}$ \\
\hline Unexposed controls & - & - & - & - & - & - & - \\
Low-level extension & - & + & - & - & + & - & + \\
High-level extension & + & ++ & ++ & + & $+(+)$ & + & $+(+)$ \\
Low-level flexion & ++ & ++ & ++ & ++ & ++ & ++ & ++ \\
\hline
\end{tabular}

Immunohistochemical visualization of GFAP at 1 week after exposure, compared to unexposed controls. All rabbits exposed to high-level flexion succumbed to the injury.

- , same GFAP immunoreactivity as that seen in unexposed animals; + , slightly increased GFAP immunoreactivity; $+(+)$, moderately increased GFAP immunoreactivity, but not in all animals; ++ , moderately increased GFAP immunoreactivity compared to unexposed animals; GFAP, glial fibrillary acidic protein.

slides and processed in parallel. Microscopic evaluation of the stained sections was performed using a Zeiss Axiomat light microscope (Carl Zeiss, Jena, Germany). Additional freefloating sections were processed as described above, but the secondary antibodies were replaced by FITC-labeled ones (Zhu et al., 2003, 2005). A Bio-Rad MRC 1024 CSLM device was utilized for confocal laser scanning microscopy (Bio-Rad Laboratories, Inc., Hercules, CA). The preparation of the sections was carried out by independent contractors, and the light microscopic evaluation was done independently by two investigators.

\section{Results}

\section{General observations}

None of the rabbits exposed to a high-level flexion trauma survived, in spite of revival efforts. In contrast, all animals survived after a low-level flexion, as well as after either a lowor a high-level extension trauma. The latter ones breathed spontaneously after an apnea period of less than $15 \mathrm{sec}$. None had any persistent deformation of the soft tissue or any skeletal fractures or dislocations. The heart rate was normalized within $10 \mathrm{~min}$. The animals were kept anesthetized during the exposure, and for at least $10 \mathrm{~min}$ thereafter. When examined $5 \mathrm{~min}$ after an extension trauma, the animals showed a positive light reaction and pain avoidance, while those exposed to a low flexion remained slow for another 4$5 \mathrm{~min}$. Those exposed to a high-level flexion did not react to light or pain stimulation, and never regained breathing. All surviving rabbits seemingly behaved normally after having recovered from the anesthesia, and their food and water consumption was normal. None of those surviving for a week or the sham animals lost weight.

Autopsy performed $30 \mathrm{~min}$ after exposure to a high-level flexion $\left(193 \pm 10.5 \mathrm{krad} / \mathrm{sec}^{2}\right)$ revealed extensive meningeal and parenchymal hemorrhages throughout the brain, extending to the cervical spinal cord, and all those animals succumbed within minutes. No lacerations or torn structures were seen. In contrast, all animals survived after a low-level flexion $\left(97 \pm 13.9 \mathrm{krad} / \mathrm{sec}^{2}\right)$, and after extension at either a high $\left(193 \pm 10.5 \mathrm{krad} / \mathrm{sec}^{2}\right)$ or a low level. A low-level flexion trauma caused rupture of scattered cortical veins and the generation of small petechiae in the leptomeninges, as well as small, superficial leptomeningeal hemorrhages at the transition between the cervical spinal cord and the brainstem. The C1 and occasionally the C2 dorsal roots were teased, but not completely ruptured. The olfactory bulbs and the olfactory nerve bundles were in part detached from the cribriform plates, and petechiae were seen on the interface. The brains from rabbits exposed to an extension trauma at either a low or a high level appeared similar to those from sham-exposed animals. There were no hemorrhages in the meninges or in the brain parenchyma, and no signs of mechanical distortion or deformation.

All rabbits in the second group survived for a week, and were then anesthetized once more and fixed by perfusion. Autopsy revealed no persistent blood clots or residues of hemorrhages, or any signs of contusion, regardless of whether the exposure was a flexion at a low level or an extension at a low or high level. It should be emphasized that no rabbits survived a high-level flexion trauma, and thus no specimens were available.

\section{Neurofilament immunohistochemistry}

There was barely any distinct immunoreactivity (IR) of the heavy subunit of neurofilaments (NF-H) demonstrable in either sham-exposed or normal brains (Fig. 1A and Table 2). In contrast, NF-H IR material accumulated in nerve cell perikarya in the cerebral cortex, most prominently in layers III and $\mathrm{V}$, at 1 week after a high-level extension trauma (Fig. 1B). The proximal parts of the apical dendrites of such neurons also showed heavy NF-H IR. Closer inspection revealed accumulation of NF-H IR in irregular, tortuous dendrites (Fig. 1C). Dendrites as well as axons emerging from the base of the pyramidal nerve cells similarly showed an irregular outline and uneven distribution of NF-H IR, which was not demonstrable in either the sham-exposed or control animals. In the corpus callosum and throughout the white matter, scattered swollen terminal stumps of disconnected neurites were seen 1 week after low-level flexion, as well as after high-level extension trauma (Fig. 1D-F). Large pyramidal neurons dispersed among normal-appearing nerve cells in the CA1 and CA3 regions of the hippocampus showed very strong NF-H IR at 1 week after trauma exposure (Table 2).

Bundles of neurites in the subcortical white matter turned at the corpus callosum at a right angle, and were difficult to visualize with NF-H immunohistochemistry in the normal brain (Fig. 2A). However, after a low-level extension trauma (Fig. 2B), and most evidently after low-level flexion trauma, these angled nerve processes displayed moderate to intense NF-H IR (Fig. 2C and D). When examined in more detail, axons with abnormal NF-H IR were seen to be arranged in bundles (Fig. 2D). 


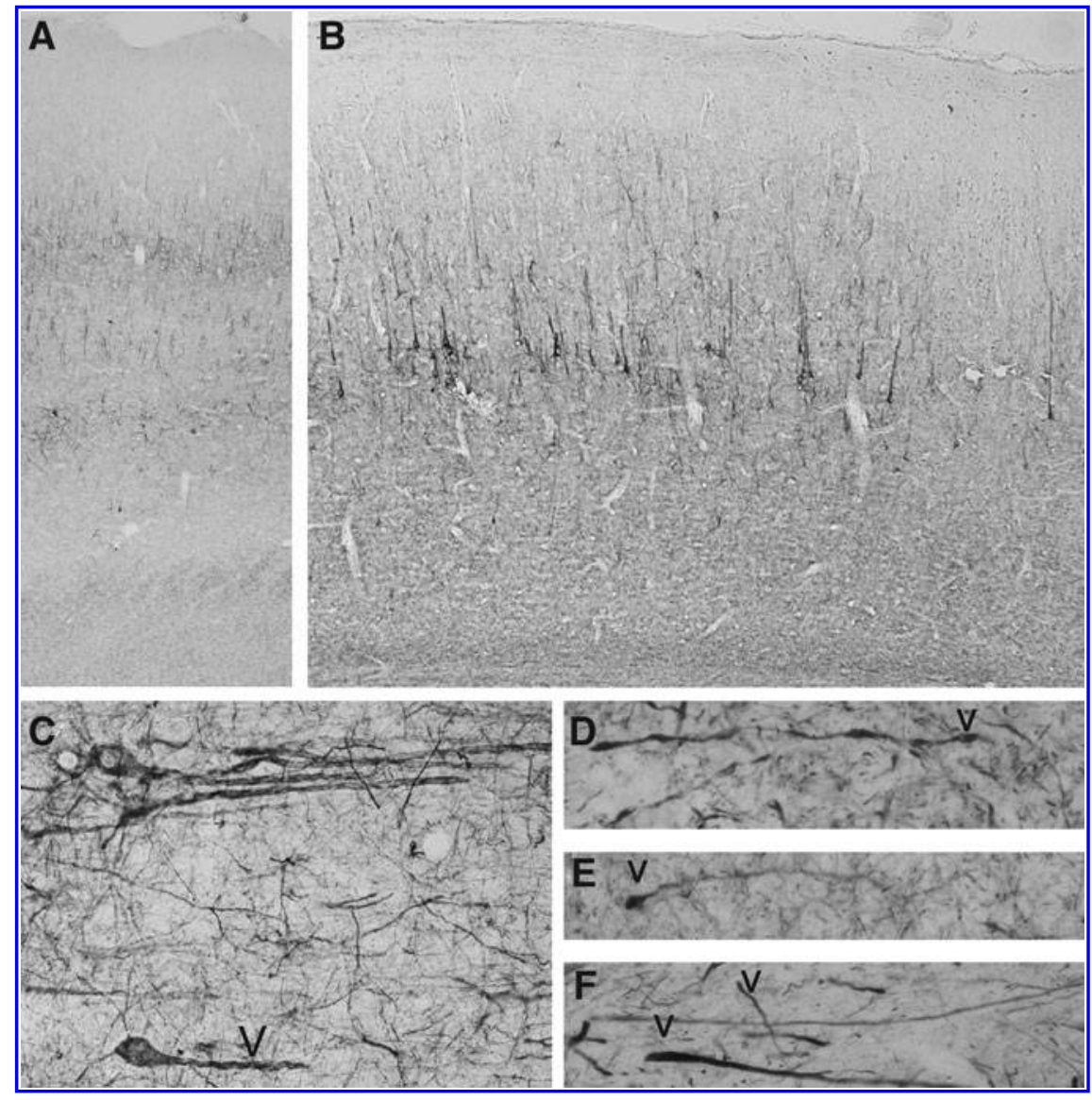

FIG. 1. Immunoreactivity (IR) for heavy subunit of neurofilaments (NF-H) in sections of rabbit brains (peroxidase technique). (A) Image showing that the neurons in the normal parietal cortex are expressing very little NF-H IR. The brain surface is at the top and the corpus callosum is below. (B) In contrast, at 1 week after exposure to a high-level rotational acceleration extension trauma, abundant NF-H IR material has accumulated in many nerve cell perikarya, most evidently in layers III and $\mathrm{V}$ of the parietal cortex. However, unstained neurons outnumber stained neurons. (C) This higher-magnification image of a portion of B shows an irregular distribution of the NF-H IR material (arrowhead) in the distorted, tortuous apical dendrites of cortical pyramidal nerve cells. (D) An irregular neurite (arrowhead) in the parietal white matter looks like a string of beads. (E) A swollen terminal stump (arrowhead) of a disconnected neurite in the corpus callosum is shown after a low-level flexion trauma, and (F) in the striatum (arrowheads), after a high-level extension trauma.

A different NF-H IR pattern was seen in the neurons in the medulla oblongata in brains not exposed to trauma, as both the perikarya and the neurites were outlined in sham-exposed and in unexposed normal rabbit brains (Fig. 2E). In contrast, 1 week after a sagittal rotational acceleration high-level extension trauma, or a low-level flexion trauma, the NF-H IR became granular and concentrated in the perikarya, and appeared as strings of beads in the proximal parts of neuronal processes (Fig. 2F-I). The NF-H IR was further rearranged compared to the normal pattern, as they formed bundles separated by nonreactive cytoplasm (Fig. $2 \mathrm{H}$ and I). Numerous neurites were enlarged, distorted, and distended by the NF-H IR material (Fig. 2J). Scattered mitral neurons in the olfactory bulbs showed NF-H IR in sham-exposed and normal brains (Fig. 3A). Exposure to a low-level extension sagittal rotational acceleration trauma increased the number of neurons, most evidently mitral neurons, displaying NF-H IR (Fig. 3B and Table 2), and a low-level flexion trauma induced a further increase in the number of stained neurons (Fig. 3C and D).

In the normal cerebellum the Purkinje nerve cell perikarya showed moderate NF-H IR, extending into the proximal parts of the dendrites (Fig. 4A and C and Table 2). A low-level flexion trauma induced at 1 week strong NF-H IR, not only throughout the Purkinje nerve cells, but also in the parallel fibers, particularly in the deeper half of the molecular layer (Fig. 4B and D). In addition, there was an increased number of stained neurites in the granular layer (Fig. 4D), which were barely seen in normal animals (Fig. 4C). Detailed light microscopy of specimens at 1 week after a low-level flexion trauma revealed increased numbers of tortuous, distorted axons with swellings and discontinuities, especially of the parallel fibers, as well as of climbing fibers and granule cell dendrites (Fig. 5B and C). An extension trauma at either level induced less-extensive changes (Fig. 5A and E and Table 2). Similarly altered staining patterns were seen in the paraflocculus. It should be stressed that in the normal rabbit brain the parallel fibers display small, regularly distributed varicosities with a smooth contour, as previously reported for other species (Nolte, 2008; Palay and Chan-Palay, 1974), which was taken into account when we evaluated the alterations seen after trauma exposure. In the brainstem, neuronal perikarya and distorted, tortuous neurites with distinct NF-H 

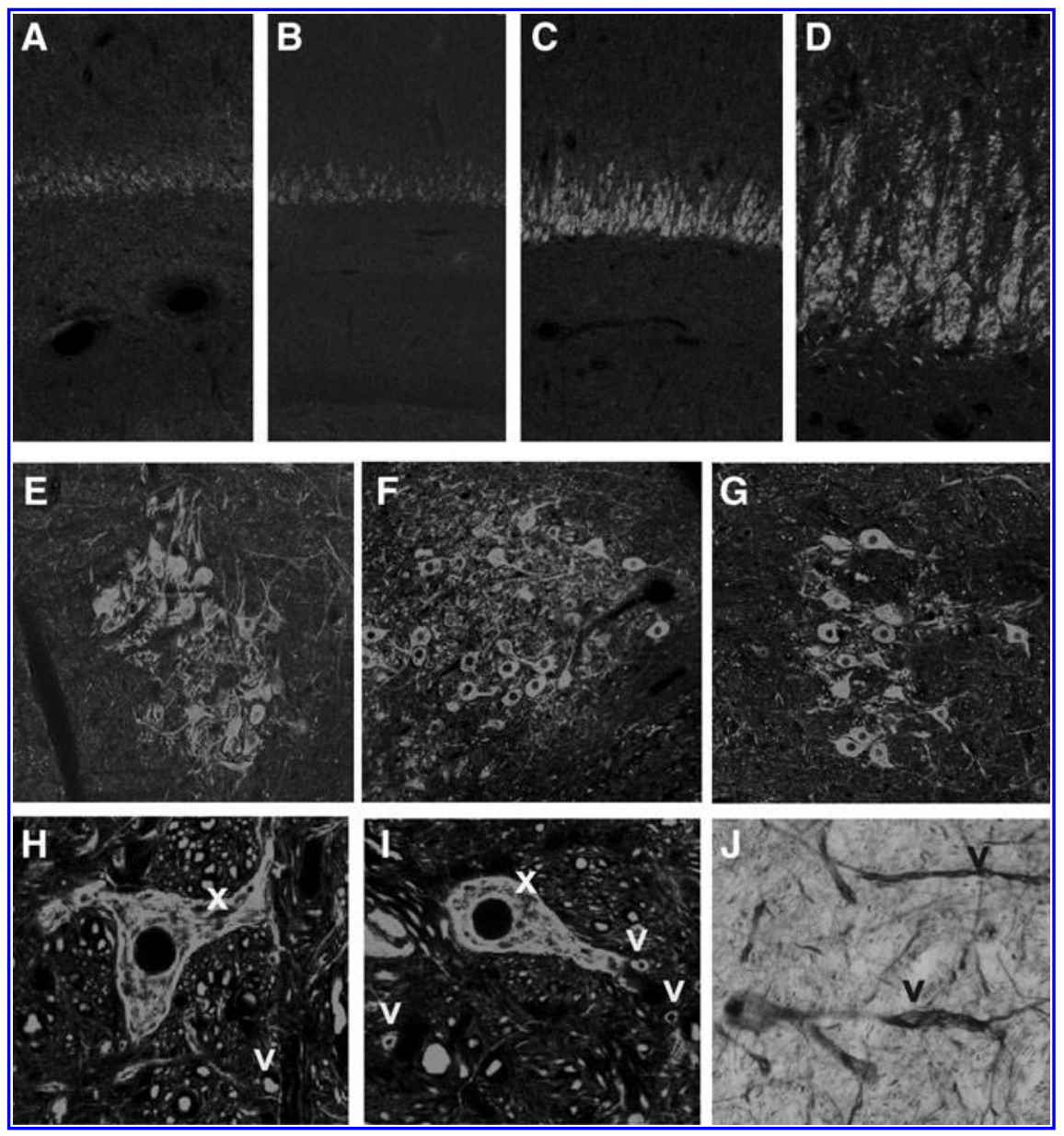

FIG. 2. Confocal laser microscopy of the parietal cortex processed for demonstration of immunoreactivity (IR) for heavy subunit of neurofilaments (NF-H). (A) Image of an unexposed rabbit brain, demonstrating slight NF-H IR in the white matter, where the axons turn just above the unstained corpus callosum (at bottom). (B) Image showing that exposure to a low-level extension after 1 week resulted in a slight increase in NF-H IR in the deeper parts of the white matter. (C) In contrast, distinctly increased NF-H IR is seen in the white matter after a low-level flexion trauma. (D) This higher-magnification image of a portion of $\mathbf{C}$ shows that the neurites in this region are assembled in bundles, many of which show very high NF-H IR. The corpus callosum is shown at the lower parts of the images. (E-I) Confocal laser microscopy of sections from the medulla oblongata processed for demonstration of NF-H IR. (E) Image revealing that moderate NF-H IR is distributed throughout the nerve cell perikarya and the delicate processes from a normal, unexposed rabbit. (F) Image showing that at 1 week after a high-level extension trauma, the NF-H IR is enriched in the perikarya and restricted to the proximal neurites. (G-I) Exposure to low-level flexion resulted in accumulation of NF-H IR in the perikarya and in the basal parts of the distended processes. $(\mathbf{H}$ and I) At higher magnification, aggregates of NF-H IR material (indicated by " $x$ ") can be seen in the nerve cell bodies. (J) The irregular accumulation of NF-H IR is also demonstrable in peroxidase processed sections (arrowheads).

IR were observed after a flexion as well as an extension trauma (Fig. 5D). When we examined the C1 and C2 levels of cervical spinal cord neurites (e.g., motor fibers), they were irregular and swollen, demonstrating NF-H IR, most prominently after a low-level flexion trauma (Fig. 5F).

\section{$\beta$-Amyloid precursor protein immunohistochemistry}

No distinct $\beta$-APP IR was seen in any neurons in the brains or spinal cords from sham-exposed and normal rabbits. With exposure to a sagittal rotational acceleration extension at a low level after 1 week, we found scattered neurons in the cerebral cortex and in the pyramidal cell layer in the hippocampus that were positive for $\beta$-APP (Fig. 6A and Table 3). Such areas in the CA1, and to a lesser extent in the CA3, regions in the hippocampus displayed not only $\beta$-APP IR, but also GFAP IR, supporting our interpretation of the prevalence of injury (Fig. 6B).

In the cerebellum, the normally non-reactive Purkinje nerve cells (Fig. 6C and Table 3) turned distinctly positive at 1 week after exposure to a sagittal rotational acceleration trauma (Fig. $6 \mathrm{D}$ and E). Low-level flexion caused more Purkinje cell $\beta$-APP IR than did extension at either level (Table 3). A higher number of $\beta$-APP IR Purkinje cells was seen in the superficial parts of the folia than deep in the fissures.

\section{GFAP immunohistochemistry}

Scattered slender astrocytes expressing GFAP IR could be identified in the superficial, molecular layer of the cerebral cortex of unexposed control animals. Such cells were only rarely seen in the blood vessels in the middle and deeper 

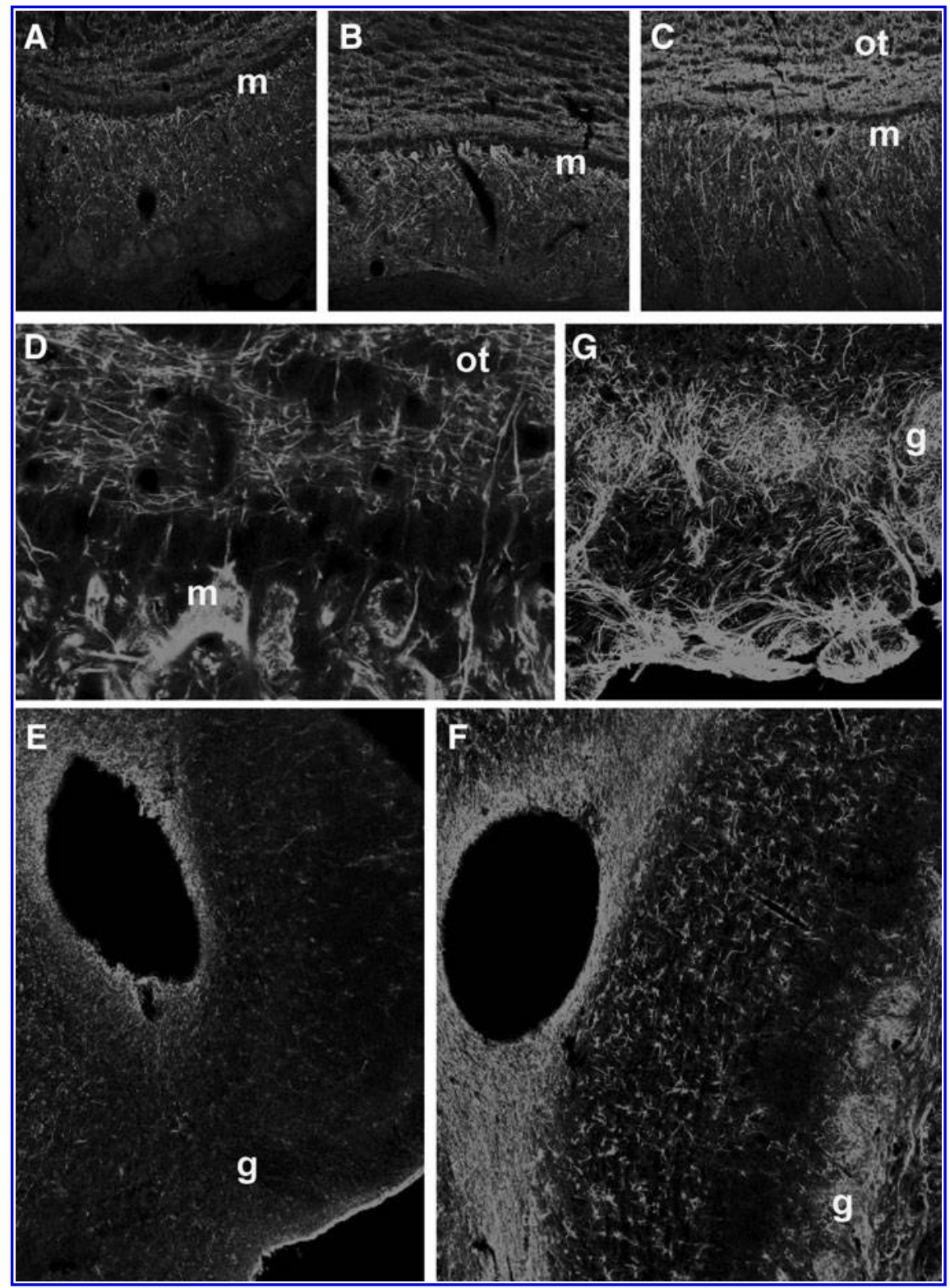

FIG. 3. Confocal laser microscopy of the olfactory bulb processed for demonstration of immunoreactivity (IR) for heavy subunit of neurofilaments (NF-H; A-D), and glial fibrillary acidic protein (GFAP; E-G). (A) Image from a rabbit at 1 week after exposure to a low-level extension trauma, showing a pattern no different from that seen in the controls. Mitral cells are indicated by " $\mathrm{m}$," and the olfactory tract by "ot." High-level extension at 1 week caused increased neuronal NF-H IR (B), while low-level flexion further increased the NF-H IR, both in neurites and in mitral nerve cell perikarya (C). (D) A highermagnification view of a portion of $\mathbf{C}$ shows that numerous neurites demonstrated NF-H IR, which was not seen in unexposed specimens. (E) Image showing that scattered stained astrocytes can be seen throughout the olfactory bulb after exposure to a low-level extension trauma, a pattern no different from that seen in normal animals. The olfactory ventricle is seen in the center as a dark hole, bordered by stained astrocytes. (F) Exposure to a low-level flexion trauma increased at 1 week the number of GFAP-IR astrocytes. Note the enrichment of GFAP IR in the olfactory glomeruli (g), at the lower right margin. (G) Higher-magnification image of a portion of $\mathbf{F}$, showing that numerous hypertrophic astrocytes outline the interface to the (detached) cribriform plate (lower margin).

portions of the normal cerebral cortex (Fig. 7A and Table 4). Animals exposed to rotational acceleration showed at 1 week an increased frequency of hypertrophic astrocytes, which were often arranged in clusters and scattered throughout the cerebral cortex, as can be seen for the low-level extension and low-level flexion groups (Fig. 7B-F). Flexion at a low level (Fig. 7C and D) induced more prominently increased GFAP IR than did extension (Fig. 7B and Table 4). Further, different patterns were observed in adjacent cortical areas, as illustrated by the prominent astrocytosis evident in a middle portion of the parietal cortex (Fig. 7C), while at just $5 \mathrm{~mm}$ laterally along the same coronal plane, the temporal cortex showed less reactivity (Fig. 7D). It must, however, be stressed that the white matter and the deep cortex in both of these areas 

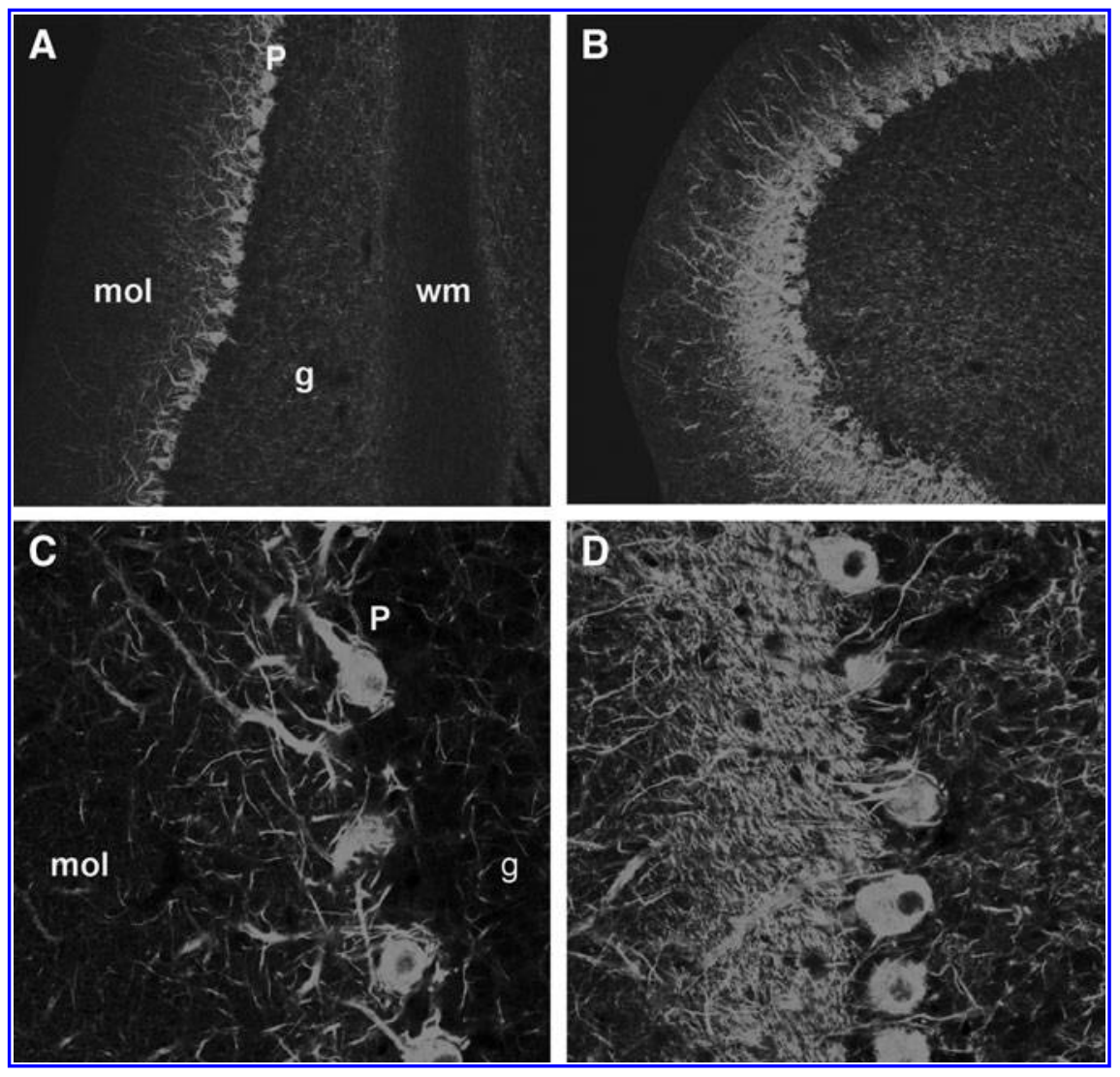

FIG. 4. Confocal laser microscopy of cerebellar tissue processed for demonstration of immunoreactivity (IR) for heavy subunit of neurofilaments (NF-H). (A) Image showing that in a normal rabbit brain the large Purkinje nerve cells express moderate to high NF-H IR in the perikarya and in proximal parts of their dendrites. The white matter (wm) is non-reactive. (B and D) Exposure to a low-level flexion trauma induced at 1 week increased NF-H IR, not only in the Purkinje neurons, but also in the parallel fibers in the molecular layer (mol) bordering the Purkinje cells (P). Axons in the granule cell layer (g) also became NF-H IR. Thus at 1 week, the trauma induced three distinct reactive changes in NF-H IR (B and D), compared to the NF-H IR seen in the normal cerebellum (A and C). First, the Purkinje cell dendrites showed elevated NF-H IR extending far into the small branches. Second, there was an increased number of intensely labeled parallel fibers in the deeper portion of the molecular layer. Third, the climbing fibers and the proximal processes from granule cells to the right distinctly expressed NF$\mathrm{H}$ IR at 1 week after trauma.

displayed distinctly increased GFAP IR (Fig. 7B-D and Table 4). In the dentate gyrus and in the pyramidal nerve cell layer of the hippocampus, hypertrophic astrocytes were seen after a low-level extension trauma (Fig. 6B), and more prominently after exposure to a high-level extension trauma or low-level flexion trauma. Hypertrophic GFAP IR astrocytes were seen in the olfactory bulbs and tracts after a rotational acceleration trauma, most evidently after a low-level flexion trauma (Fig. $3 \mathrm{~F}$ and $\mathrm{G})$, compared to that normally seen (Fig. 3E). Astrocytes in the glomeruli in the olfactory bulbs became hypertrophic and expressed intense GFAP IR (Fig. 3F and G).

We further investigated the column of fornix, a bundle comprising axons that form a prominent output pathway from the hippocampus (Nolte, 2008), with regard to the prevalence of gliosis. As reported above, injured neurons were demonstrable in the hippocampus at 1 week after trauma exposure. We therefore analyzed the prevalence of hypertrophic, reactive astrocytes along the path of axons originating from the damaged hippocampal pyramidal nerve cells, as degenerating axons should induce reactive alterations in supporting glial cells. Slight GFAP IR was expressed by scattered slender astrocytes in the columna fornici in a normal brain, enabling its identification (Fig. 7G and Table 4). A highlevel extension trauma, and most evidently a low-level flexion trauma, increased GFAP IR, distinctly outlining the columna fornici (Fig. 7H and I and Table 4), revealing the predicted axonal damage. Closer inspection at higher magnification disclosed that the normally slender astrocytes had become hypertrophic, and formed a meshwork of interconnected distinct processes. Further, there was an increased prevalence of hypertrophic astrocytes in the cerebral white matter, corpus callosum, and the brainstem, in brains from animals at 1 week after a sagittal rotational acceleration exposure.

In the cerebellum a sagittal rotational acceleration exposure induced at 1 week increased numbers of enlarged astrocytes (Fig. 7K and Table 4), compared to those seen in shamexposed and unexposed animals (Fig. 7J). Closer inspection revealed that many enlarged, arborized astrocytes were prevalent throughout the granule layer, most evidently at the Purkinje cells, and also in the white matter (Fig. 7M), compared to normal animals (Fig. 7L). Prominent GFAP IR processes from the Bergmann radial glia cells enveloped the 


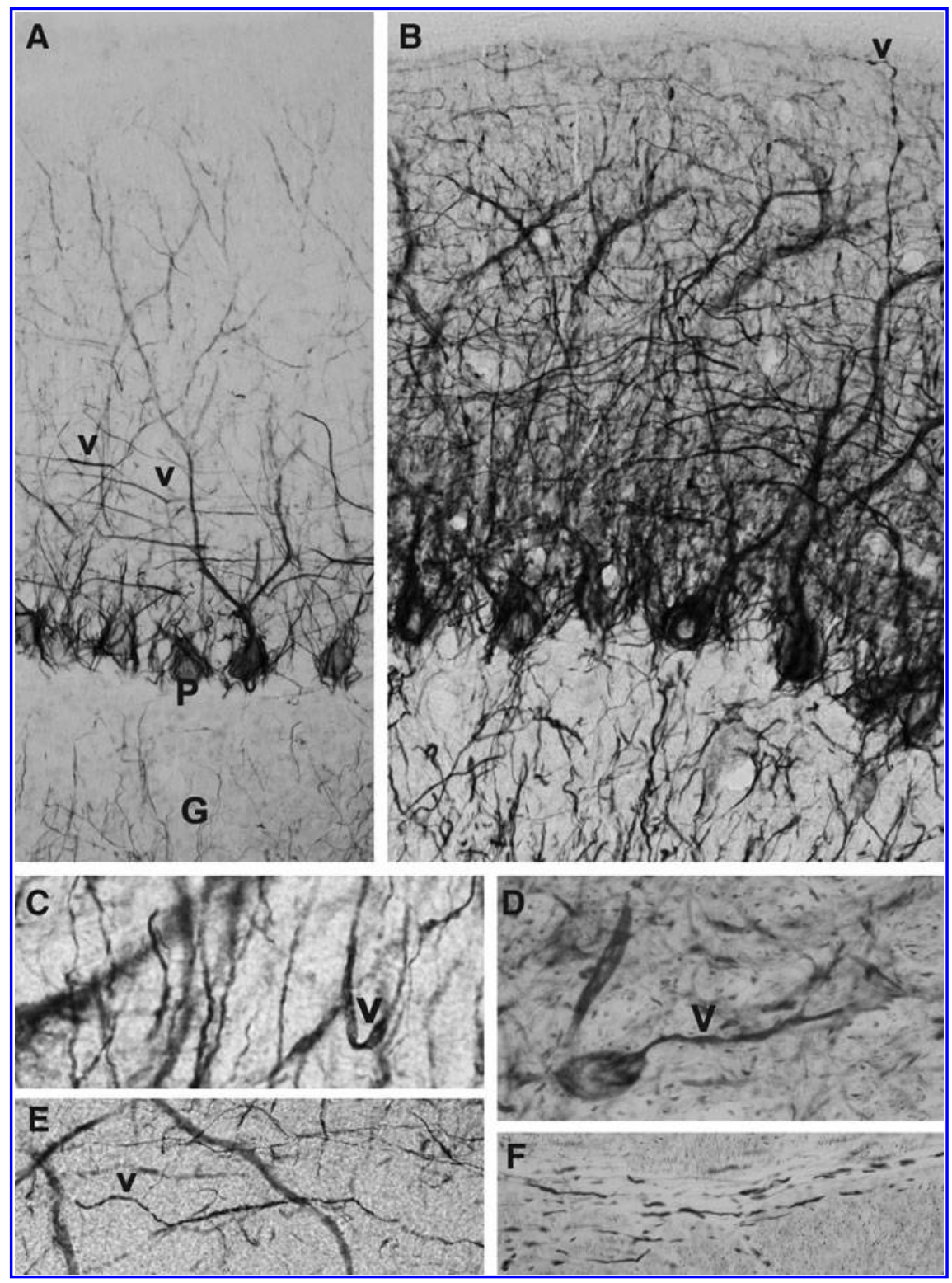

FIG. 5. Light micrographs of sections processed for immunoreactivity (IR) for heavy subunit of neurofilaments (NF-H; peroxidase technique). (A) Image revealing that parallel fibers in the vermis of cerebellum were swollen and irregular (arrowheads), and expressed NF-H IR at 1 week after exposure to a low-level extension trauma. Note that very few stained processes can be seen in the granule layer $(\mathrm{G})$ at the base of the Purkinje nerve cell $(\mathrm{P})$. (B) In contrast, exposure to a low-level flexion trauma induced at 1 week a strong increase in NF-H IR in numerous tortuous and irregular parallel fibers (arrowhead). Note the irregular, tortuous NF-H IR processes in the granule layer approaching the base of the Purkinje nerve cells. (C and E) Higher-magnification imaging showing the abnormally tortuous and irregularly outlined parallel fibers (arrowheads) in a specimen from the paraflocculus shown in B. (D) An axon with a string of elongated varicosities (arrowhead) from the cerebellar deep nuclei at 1 week after a high-level extension trauma. (F) Motor fibers (C1) became irregular and swollen, and displayed abnormally increased NF-H IR, at 1 week after a low-level flexion trauma.

Purkinje nerve cells, and extended to the superficial limiting glial membrane (Fig. 7J-M). Low-level flexion induced more extensive reactive changes than did extension at either level (Table 4).

\section{Discussion}

The experimental system we developed enabled the exposure of the head and neck of an anesthetized rabbit to a sagittal rotational acceleration impulse, exerted either as a very rapid flexion or extension movement. The same load was applied at either of two levels, but in opposite directions. A key finding was that the outcome differed depending on the direction of the movement at identical loads. The exposure of an animal to high-level flexion stopped its breathing and cardiac activity, and all revival attempts failed (i.e., all of the rabbits succumbed within minutes). A low-level flexion exposure induced at 1 week more extensive histopathologically demonstrable reactive changes in the brain and cervical spinal cord than did extension at the same applied load. The 

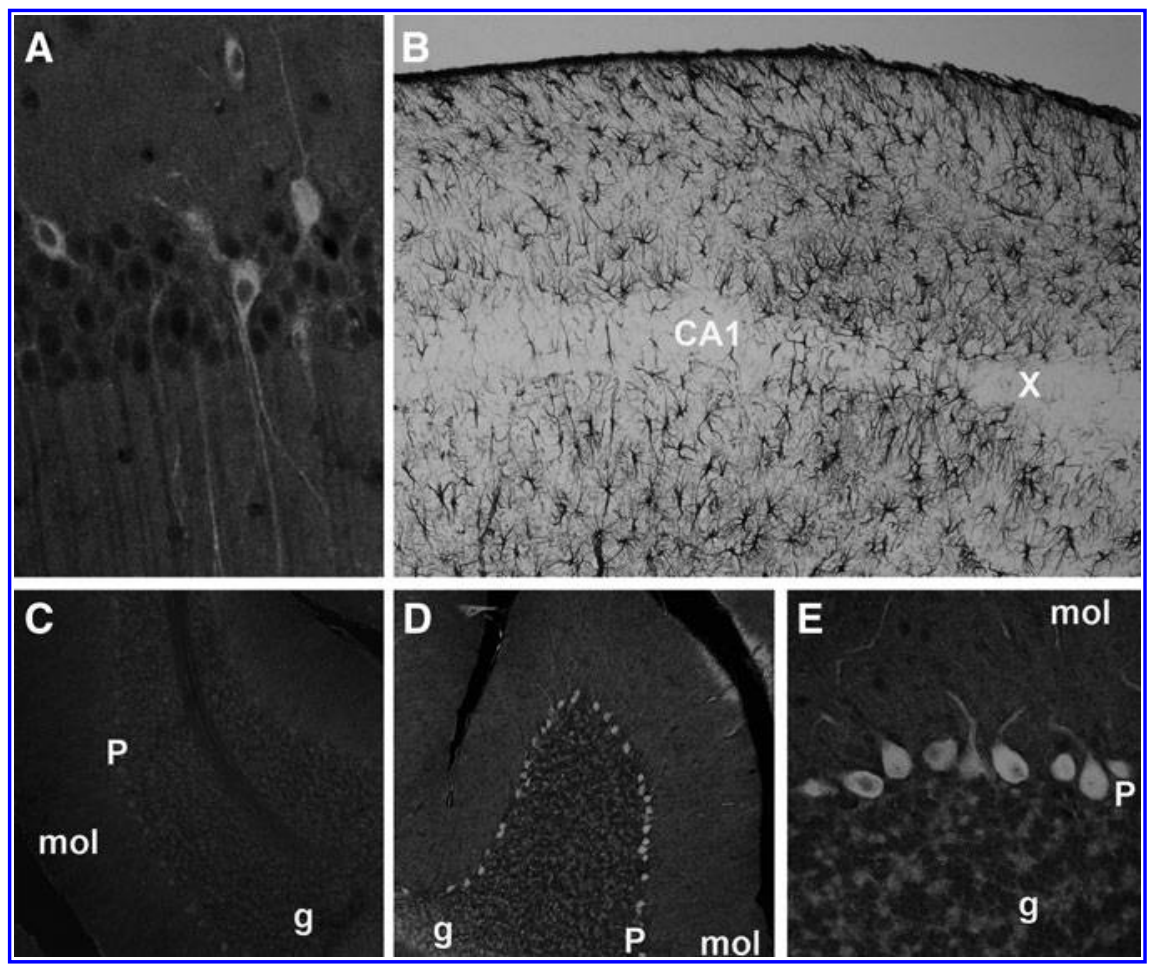

FIG. 6. (A) Confocal laser micrograph of $\beta$-amyloid precursor protein ( $\beta$-APP) immunoreactivity (IR) in nerve cells in the CA3 region of the hippocampus at 1 week after a low-level extension trauma, which were not seen in the normal brain. (B) Processing a similar specimen (peroxidase technique) for glial fibrillary acidic protein (GFAP) IR reveals gliosis in a narrow section of the pyramidal nerve cell layer (between CA1 and " $\mathrm{X}^{\prime \prime}$ ). The specimens shown in $\mathbf{C}, \mathrm{D}$, and $\mathbf{E}$ were processed for demonstration of $\beta$-APP IR in the vermis cerebelli. The exposure to a low-level extension trauma induced at 1 week high $\beta$ APP IR in almost all Purkinje nerve cells (P), a finding not seen in a section from a sham-exposed animal (C). Occasional cells in the granular layer $(\mathrm{g})$ turned positive as well (D). (E) Higher magnification image of a portion of D, showing that the Purkinje nerve cells are filled with $\beta$-APP IR, which extends into the dendrites in the molecular layer (mol).

difference was striking, as flexion at a low level induced extensive reactive alterations, while a low-level extension resulted in only minor changes with a restricted distribution. We thus conclude that the same applied forces resulted in different extents and distributions of DBI, depending on the direction. The same was true when comparing the macroscopically visible signs of structural injury seen $30 \mathrm{~min}$ after exposure to a sagittal rotational acceleration trauma. A lowlevel flexion trauma generated meningeal hemorrhages, occasional rupture of veins, and tearing of the olfactory nerves, while such acute gross damage was not seen after exposure to an extension at the same level. Such injuries are likely to be related to mechanical trauma due to the induced motion of the brain and the spinal cord in relation to the skull and the vertebral column (Bayly et al., 2006; Gosch et al., 1970; Greenberg, 2010; Leestma, 2008; Oehmichen et al., 2005; Pudenz and Sheldon, 1946; Sabet et al., 2008). It is tempting to postulate that the dislocation of the brain and the spinal cord in relation to their enclosures and attachments differed considerably at low-level flexion from that occurring with extension. In the rabbit, the brain and attached spinal cord impact different bone structures and membranes, depending on the direction of the movement. Further, the cranial nerves and the spinal nerves, as well as the falx and the tentorium cerebelli, are likely to exert different mechanical loads on nervous tissue, depending on the direction of movement. When translating the results achieved for the rabbit brain and spinal cord to human injury, additional factors must also be considered. The rabbit brain is lissencephalic (i.e., smooth-surfaced), while the human brain is gyrencephalic (i.e., convoluted). The brain weight in the adult rabbit is just $0.01 \mathrm{~kg}$, compared to $1.4 \mathrm{~kg}$ in humans (Nolte, 2008), and the ratio between the brain and body weights also differ. The fairly straight neuraxis in rabbits differs from the distinctly angled one seen in humans. Further, the relative proportions of the different brain areas differ considerably. One therefore must be cautious when discussing and evaluating the results achieved in rabbit experiments with their potential relevance to human injury. Case reports indicate that flexion trauma to the head and neck in humans results in more extensive damage than extension trauma (Leestma, 2008; Oehmichen et al., 2005), a finding in agreement with our results. Based on forensic medicine investigations, Leestma (2008) stated that the direction of a trauma applied to a human head has great significance with regard to the resulting brain damage. In our opinion, a cautious interpretation based on the available data indicates that a flexion trauma is more deleterious to the central nervous system than an extension trauma, for both rabbits and humans.

We have in separate studies reported that transient, rapid, and dynamic pressures are generated with the exposure of the head and neck to a sagittal rotational acceleration impulse (Krave et al., 2005, 2010). A low-level flexion, lasting about $1 \mathrm{msec}$, induced strong underpressures with a duration of up to $25 \mathrm{msec}$. Extension at a high level generated more promi- 


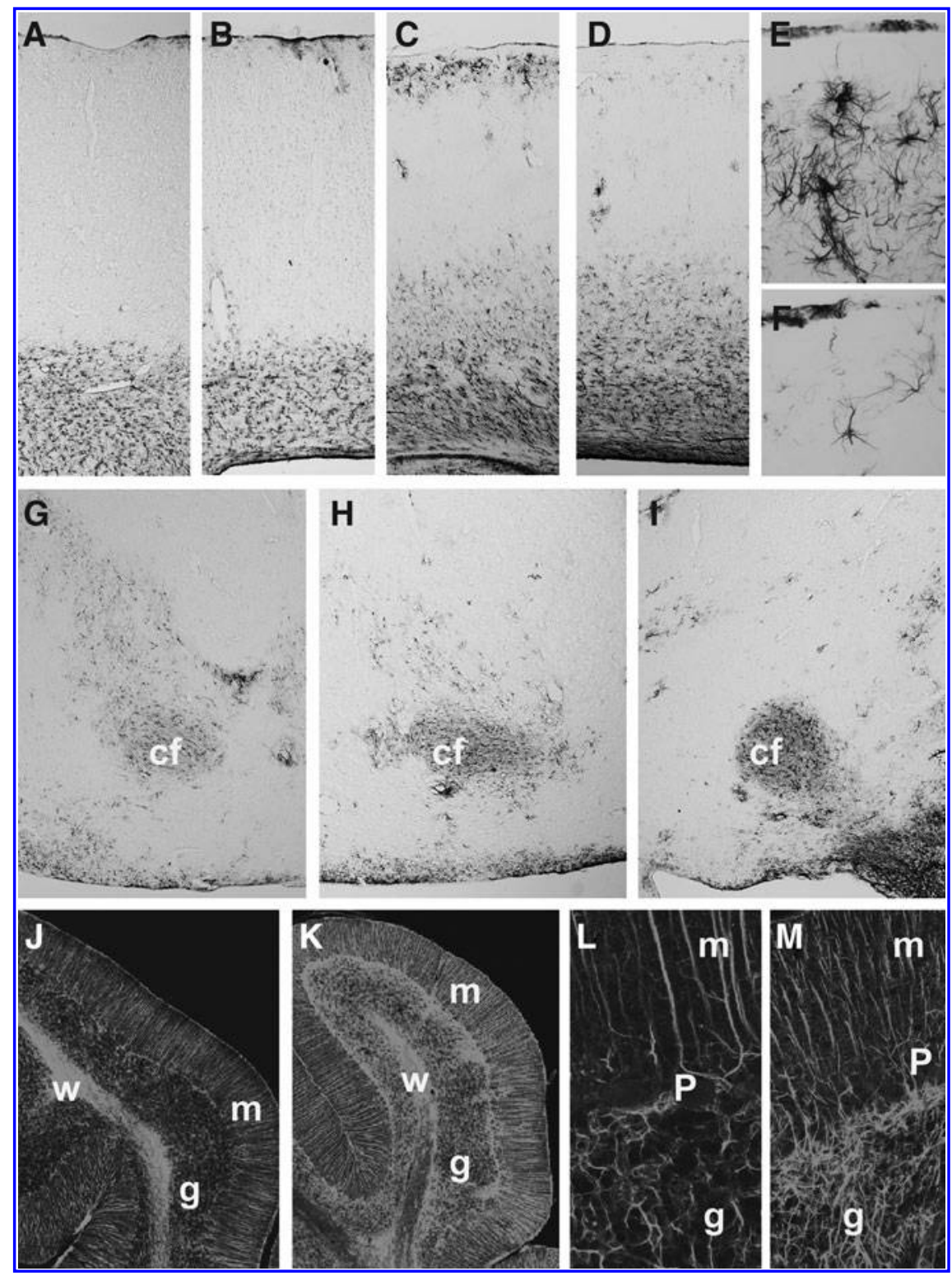

FIG. 7. Light micrographs of sections processed for demonstration of glial fibrillary acidic protein (GFAP) immunoreactivity (IR; peroxidase technique shown in $\mathbf{A}-\mathbf{I}$; confocal microscopy shown in $\mathbf{J}-\mathbf{M}$ ). In the normal parietal cortex there were few stained astrocytes visible throughout the cortex, in contrast to the many small GFAP IR astrocytes seen in the medulla (at the bottom of A). (B) Exposure to a low-level extension trauma induced at 1 week GFAP IR in some astrocytes in the cortex, particularly in the blood vessels. (C and D) However, exposure to a low-level flexion trauma increased the prevalence of GFAP IR astrocytes in the parietal cortex, both in the outer granular layer and in the deeper cortical layers. Further, there was an increased frequency of hypertrophic astrocytes in the white matter. In contrast, there was no corresponding increased frequency of GFAP IR astrocytes in adjacent superficial parts of the temporal cortex (D), as seen in this image from the same brain and hemisphere as the specimen shown in $\mathbf{C}$. Note the prevalence of marked regional differences in the distribution of the gliosis. (E and F) Higher-magnifications of portions of $\mathbf{C}$ and $\mathbf{D}$, respectively. Note that the astrocytes in the outer granular layer in $\mathbf{C}$ and $\mathbf{E}$ are hypertrophic, in contrast to the tiny, normal-appearing ones seen in $\mathbf{D}$ and $\mathbf{F}$. (G) The astrocytes in the columna fornici (cf) in a normal brain show slight GFAP IR, enabling its identification. (H) A low-level flexion trauma caused at 1 week increased GFAP IR, and the columna fornici were more distinctly outlined, indicating reactive changes. (I) A lowlevel flexion trauma induced the generation of numerous hypertrophic astrocytes, which were preferentially localized in the columna fornici (cf). (J) Image showing the distribution of GFAP IR astrocytes in a normal rabbit cerebellum. Tiny Bergmann astrocytes extend through the molecular layer $(\mathrm{m})$. Additional stained astrocytes are seen in the granule cell layer $(\mathrm{g})$, and in the white matter $(w)$. (K) A low-level flexion trauma caused prominently increased GFAP IR, most prominently in the granule cell layer facing the molecular layer $(\mathrm{m})$. ( $\mathbf{L}$ and $\mathbf{M})$ Higher-magnification images of portions of $\mathbf{J}$ and $\mathbf{K}$, respectively. Increased GFAP IR in the granular layer $(\mathrm{g})$ at the base of the Purkinje nerve cells $(\mathrm{P})$ can be seen, as is the increased density of Bergmann radial glia processes extending through the molecular layer $(\mathrm{m})$. 
nent pressure changes than those seen with exposure at a low level, mainly comprising overpressure peaks, followed by underpressures. Our immunohistochemical investigations demonstrated that exposure to a sagittal flexion rotational acceleration induced more severe and widely distributed DBI than did extension at the same load. We believe that the generation of rapid, dynamic underpressures is likely to contribute to the demonstrated DBI, as most prominently illustrated by the difference in outcomes seen after a low-level flexion and a low-level extension trauma (Tables 2, 3, and 4). Extension resulted in the generation of first an overpressure peak, followed by underpressures of lower amplitudes and shorter durations than the pressures recorded after a flexion. Trains of overpressures and underpressures, when induced at a distance from the brain, have previously been reported to cause DBI and diffuse axonal injury (DAI) (Suneson et al., 1990). Pressure waves have been recorded in the brain with the exposure of animals to blasts and impulse noise, and have been linked to brain injuries (Chavko et al., 2007; Elsayed and Atkins, 2008; Ling et al., 2009; Säljö et al., 2000). We postulate that the dynamic pressures generated by a sagittal rotational acceleration trauma are likely to contribute to the generation of DBI and DAI. Further, there appears to be a correlation between the extent and severity of the TBI and the pressure dynamics, most evidently the underpressures.

We utilized two impulse levels for each of the two sagittal loading directions, flexion and extension. The peak rotational acceleration is one of several kinematic parameters of an impact that may be correlated with injury severity, as is its duration. The impact conditions for our model system were scaled to those of peak accelerations in humans (Gutierrez et al., 2001). The high level of acceleration used in the present study corresponded to approximately to $11,000 \mathrm{rad} . \mathrm{sec}^{-2}$, which is thought to induce a moderate brain injury in humans (Gutierrez et al., 2001). The low-level trauma was equivalent to about 6000 rad.sec ${ }^{-2}$. These levels should be compared to the parameters of reconstructions of the biomechanics of concussions suffered by professional football players, in whom 6432 rad. $\mathrm{sec}^{-2}$ has been estimated to be the average rotational acceleration (Pellman et al., 2003). The scaled thresholds were highly dependent on the measure used, since the brain's shape and size, as well as the neuraxis, differs greatly between rabbits and humans. Further, these thresholds of injury in humans have been estimated from reconstructions, presuming global head rotation. We believe, based on the considerations noted above, that the low level of rotational acceleration exerted on the rabbits might generate a mild DBI in a human. This is in agreement with our immunohistochemical results for the low-level extension group, which was found to have a mild DBI. In contrast, for flexion trauma in the rabbit at the same low level, there was no corresponding concordance, as the DBI was revealed to be moderate to severe and widespread.

The presently used experimental set-up did not induce any brain contusions or hemorrhages in the brain parenchyma, or any extensive meningeal hemorrhages, except for the highlevel flexion group. Previous studies with a slightly different set-up generated parenchymal and subarachnoid hemorrhages, the latter extending from the base of the brain to the optic chiasm and the cervical spinal cord (Gutierrez et al., 2001; Hamberger et al., 2003; Runnerstam et al., 2001). In contrast, the set-up we used induced a DBI without any brain contusion, lacerations, or parenchymal hemorrhages. The brain damage induced by our model system differed as well in important aspects from that seen with other experimental systems, most of which cause severe focal brain damage (Cernak, 2005; Morales et al., 2005). Mild TBI is by far most common in human victims suffering a closed head and neck trauma, in contrast to the fact that most experimental systems are used to explore more severe damage (Blumbergs et al., 2008; Cernak, 2005; Greenberg, 2010; Kopapka et al., 1991; Morales et al., 2005; Ommaya et al., 2002; Reilly and Bullock, 2005). Our model system adds to the range of trauma model systems used to study the DBI and DAI seen in the most common type of TBI, concussion, which annually afflicts millions of people worldwide.

Axonal damage is a common, serious feature of TBI. In this study, we used the abnormal redistribution and accumulation of NF-H in nerve cell perikarya and neurites as a measure of DAI. The concomitant presence of GFAP-positive, reactive hypertrophic astrocytes confirmed the prevalence of the damage. The abnormal accumulation of NF-H in the neurons is due to the impaired transport of cytoskeletal material, and it takes time to evolve (Blumbergs et al., 2008; Farkas and Povlishock, 2006; Säljö et al., 2000; Smith and Meaney, 2000; Smith et al., 1997). Astrocytosis is a sensitive measure of the inflammatory reaction activated at sites of brain injury, and correlates with neuronal and axonal damage (Barres, 2008; Blumbergs et al., 2008; Farkas and Povlishock, 2007; Graham et al., 1995; Miller et al., 2009). Disorganization of the cytoskeleton disturbs and impairs neurons and their associated glial cells, resulting in dysfunction of the nervous system (Cullen and LaPlaca, 2006; Cullen et al., 2007; Farkas and Povlishock, 2007; LaPlaca and Prado, 2010; Stone et al., 2004). Previous studies have revealed that pressure waves lasting about $1 \mathrm{msec}$, of roughly the same magnitude as those seen in our study, can impair the neuronal cytoskeleton (Säljö et al., 2000; Suneson et al., 1990). However, the details behind the mechanisms of injury remain to be further elucidated.

Abnormal immunoreactivity patterns were seen at 1 week post-trauma for neurons in the cerebellum at all three investigated exposure conditions. For low-level extension, the injury was detectable, but to a lesser extent than that seen after the other two loads. Variations were seen within the same areas between animals that were similarly exposed. However, one common observation was that the most prominent alterations were observed at the summit of a folium. Further, one folium could appear normal, while adjacent ones showed distinct abnormalities. However, the most extensive changes were inevitably seen after a low-level flexion trauma, while extension at a low level was at the low threshold of histopathologically demonstrable injuries. Previous studies of experimentally-induced TBI have paid the cerebellum only limited attention. The cerebellum is characterized by its notably uniform and seemingly simple structure, yet it has complex and significant functions (Nolte, 2008; Palay and Chan-Palay, 1974). Cerebellar injury is fairly common in human trauma victims, but it receives little attention in animal studies (Blumbergs et al., 2008; Cernak, 2005; Greenberg, 2010; Kilbourne et al. 2009; Leestma, 2008; Morales et al. 2005; Oehmichen et al., 2005; Reilly and Bullock, 2005). In our opinion, the cerebellum deserves more attention with regard to the prevalence of damage seen after TBI, as we demonstrated in the present study. 
The brain and the spinal cord are connected and move as a unit when exposed to a sagittal rotational acceleration of the head and neck (Bayly et al., 2006; Gosch et al., 1970; Greenberg, 2010; Leestma, 2008; Oehmichen et al., 2005; Pudenz and Sheldon, 1946; Sabet et al., 2008). The petechial hemorrhages seen at the transition between the brainstem and the spinal cord with a low-level flexion were likely due to mechanical constraints, as was the partial rupture of the uppermost cervical dorsal nerve roots. Also the dynamic pressures, which we have found to be generated by a sagittal rotational acceleration trauma (Krave et al., 2005, 2010), may contribute to injury to the cervical cord neurons. These observations indicate that the exposure of the head and neck to rotational acceleration may not only damage the brain, but also the spinal cord, the extent and distribution of which require further investigation.

The olfactory bulbs and the olfactory nerves, which in rabbits are proportionally large, were also injured by sagittal rotational acceleration trauma. The presence of petechiae, the abnormal distribution of NF-H IR, and the appearance of increased GFAP IR in the olfactory bulbs, proves that the olfactory system was exposed to an injurious load not only with flexion, but also with extension exposure (Table 2). Anosmia and a lack of olfactory function are common in humans post-TBI, and for most victims is related to injury severity (Callahan and Hinkebein, 2002; Constanzo and Miwa, 2006; de Kruijk et al., 2003; Haxel et al., 2008). Thus in our model system we were able to generate a common sequela that complicates life for a large number of TBI victims.

The exposure to a high-level sagittal rotational acceleration trauma resulted in very different outcomes, depending on whether it was a flexion or an extension. All animals subjected to a high-level flexion succumbed immediately after exposure. In contrast, none of those having had an extension injury at either level showed any signs of acute or persistent functional impairment. The cardiovascular malfunction and respiratory arrest seen after high-load flexion imply damage to the brainstem. At autopsy, multiple hemorrhages in the brain parenchyma and nervous tissue contusions were seen, most evidently in the brainstem. Pressure recordings performed with exposure to flexion at a high load disclosed that a strong, negative pressure peak was followed by repeated oscillations (Krave et al., 2010). A high mechanical load was likely thus exerted on the brainstem and the cervical cord. However, the available data do not allow any conclusions to be drawn about the possible generation of injurious cavitations and shockwaves (Elsayed and Atkins, 2008; El Sayed et al., 2008; Leestma, 2008; Oehmichen et al., 2005; Suneson et al., 1990).

In conclusion, we have demonstrated that DBI and DAI were induced by exposure to a sagittal rotational acceleration impulse, exerted as either flexion or extension. Structural alterations fulfilling the criteria for DBI were demonstrable in the cerebrum, brainstem, cerebellum, and spinal cord, with marked heterogeneity. Further, the same level of applied sagittal rotational acceleration load exerted as flexion of the head and neck resulted in more extensive and severe damage than did extension. In fact, a low-level flexion trauma induced a DBI and DAI that was more extensive and severe than that seen after a high-level extension injury. The dynamic pressures recorded at the time of trauma appeared to correlate with the severity of the DBI seen after 1 week.

\section{Author Disclosure Statement}

No competing financial conflicts exist.

\section{Acknowledgments}

We thank Dr. Hong Zhu for invaluable help with specimen preparation, examination, and evaluation; Dr. Johan Davidsson, Dr. Svante Höjer, Ms. Iris Gustafsson, Ms. Ingela Jonson, Prof. Stefan Lange, Prof. Per Lövsund, and Ms. Margareta Rosenkvist, for support, advice, and assistance.

This study was funded in part by the Swedish federal government (grant no. 71570), Sahlgrenska University Hospital (grant no. 83030), Vinnova, the Ministry of High Education United Arab Emirates, the Magnus Bergvall Foundation, the W. and M. Lundgren Foundation, FrimurareBarnhus direktionen, the Göteborg Medical Society, AB Nectin, and Lantmännen AS-Faktor AB.

\section{References}

Barres, B.A. (2008). The mystery and magic of glia: a perspective on their roles in health and disease. Neuron 60, 430-440.

Bayly, P.V., Black, E.E., Pedersen, R.C., Leister, E.P., and Genin, G.M. (2006). In vivo imaging of rapid deformation and strain in an animal model of traumatic brain injury. J. Biomechanics 39, 1086-1095.

Blumbergs, P., Reilly, P., and Vink, R. (2008). Trauma, in Greenfield's Neuropathology, 8th ed. S. Love, D.N. Louis, and D.W. Ellison (eds). Arnold: London, pps. 733-832.

Callahan, C.D., and Hinkebein, J.H. (2002). Assessment of anosmia after traumatic brain injury. J. Head Trauma Rehab. 17, 251-256.

Cernak, I. (2005). Animal models of head trauma. NeuroRx 2, 410-422.

Chavko, M., Koller, W.A., Prusaczyk, W.K., and McCarron, R.M. (2007). Measurement of blast wave by miniature fiber optic pressure transducer in the rat brain. J. Neurosci. Meth. 159, 277-281.

Costanzo, R.M., and Miwa, T. (2006). Posttraumatic olfactory loss. Adv. Otorhinolaryngology 63, 99-107.

Cullen, D.K., and LaPlaca, M.C. (2006). Neuronal response to high shear deformation depends on heterogeneity of the local strain field. J. Neurotrauma 23, 1304-1319.

Cullen, D.K., Simon, C.M., and LaPlaca, M.C. (2007). Strain ratedependent induction of reactive astrogliosis and cell death in three-dimensional neuronal-astrocytic co-cultures. Brain Res. $1158,103-115$.

de Kruijk, J.R., Leffers, P., Menheere, P.P., Meerhoff, S., Rutten, J., and Twijnstra, A. (2003). Olfactory function after mild traumatic brain injury. Brain Inj. 17, 73-78.

Elsayed, N.M., and Atkins, J.L. (2008). Explosion and Blast-Related Injuries. Elsevier: Amsterdam.

El Sayed, T., Mota, A., Fraternali, F., and Ortiz, M. (2008). Biomechanics of traumatic brain injury. Comput. Methods Appl. Mech. Engineering 197, 4692-4701.

Farkas, O., and Povlishock, J.T. (2007). Cellular and subcellular changes evoked by diffuse traumatic brain injury: a complex web of change extending far beyond focal damage. Progress Brain Res. 161, 43-59.

Faul, M., Xu, L., Wald, M.M., and Coronado, V.G. (2010). Traumatic brain injury in the United States: emergency department visits, hospitalizations, and deaths 2002-2006. Centers for Disease Control and Prevention, National Center for Injury Prevention and Control. Atlanta, Georgia, pps. 1-74. 
Gosch, H.H., Gooding, E., and Schneider, R.C. (1970). The lexan calvarium for the study of cerebral responses to acute trauma. J. Trauma 10, 370-376.

Graham, D.I., Adams, J.H., Nicoll, J.A.R., Maxwell, W.L., and Gennarelli, T.A. (1995). The nature, distribution and causes of traumatic brain injury. Brain Pathol. 5, 397-406.

Greenberg, M. (2010). Handbook of Neurosurgery, 7th ed. Thieme: Berlin.

Gutierrez, E., Huang, Y.-L., Haglid, K., Bao, F., Hansson, H.-A., Hamberger, A., and Viano, D. (2001). A new model for diffuse brain injury by rotational acceleration: I. Model, gross appearance and astrocytosis. I. Neurotrauma 18, 247257.

Hamberger, A., Huang, Y.-L., Zhu, H., Bao, F., Ding, M., Blennow, K., Olsson, A., Hansson, H.-A., Viano, D., and Haglid, K. (2003). Redistribution of neurofilaments and accumulation of $\beta$-amyloid protein after brain injury by rotational acceleration of the head. I. Neurotrauma 20, 168-179.

Haxel, B.R., Grant, L., and Mackay-Sim, A. (2008). Olfactory dysfunction after head injury. J. Head Trauma Rehabil. 23, 407-413.

Kilbourne, M., Kuehn, R., Tosun, C., Caridi, J., Keledjian, K., Bochicchio, G., Scalea, T., Gerzanich, V., and Simard, J.M. (2009). Novel model of frontal impact closed head injury in the rat. J. Neurotrauma 26, 2233-2243.

Kopapka, M.J., Gennarelli, T.A., Graham, D.I., Adams, J.H., Thibault, L.E., Ross, D.T., and Ford, I. (1991). Selective vulnerability of hippocampal neurons in acceleration-induced experimental head injury. J. Neurotrauma 8, 247-258.

Krave, U., Al-Olama, M., Davidsson, J., Höjer, S., and Hansson, H.-A. (2010). Importance of impulse direction for brain pressures response during rotational acceleration head trauma. Submitted for publication.

Krave, U., Höjer, S., and Hansson, H.-A. (2005). Transient, powerful pressures are generated in the brain by a rotational acceleration impulse to the head. Eur. J. Neurosci. 21, 28762882.

Langlois, J.A., Rutland-Brown, W., and Wald, M.M. (2006). The epidemiology and impact of traumatic brain injury: a brief overview. J. Head Trauma Rehabil. 21, 375-378.

LaPlaca, M.C., and Prado, G.R. (2010). Neural mechanobiology and neural vulnerability to traumatic loading. J. Biomech. $43,71-78$.

Leestma, J.E. (2008). Forensic Neuropathology, 2nd ed. Raven Press: New York.

Ling, G., Bandak, F., Armonda, R., Grant, G., and Ecklund, J. (2009). Explosive blast neurotrauma. J. Neurotrauma 26, 815825.

Miller, W.J., Leventhal, I., Scarsella, D., Haydon, P.G., Janmey, P., and Meaney, D.F. (2009). Mechanically induced reactive gliosis causes ATP-mediated alterations of astrocyte stiffness. J. Neurotrauma 26, 789-797.

Morales, D.M., Marklund, N., Lebold, D., Thompson, H.J., Pitkanen, A., Maxwell, W.L., Longhi, L., Laurer, H., Maegele, M., Neugebauer, E., Graham, D.I., Stocchetti, N., and McIntosh, T.K. (2005). Experimental models of traumatic brain injury: do we really need to build a better mousetrap. Neuroscience 136, 971-989.

Nolte, J. (2008). The Human Brain, 6th ed. Mosby: St. Louis.

Oehmichen, M., Auer, R.N., and König, H.G. (2005). Forensic Neuropathology and Associated Neurology. Springer Verlag: Heidelberg.
Ommaya, A.K., Goldsmith, W., and Thibault, L. (2002). Biomechanics and neuropathology of adult and pediatric head injury. Br. J. Neurosurg. 16, 220-242.

Palay, S.L., and Chan-Palay, V. (1974). Cerebellar Cortex, Cytology and Organization. Springer Verlag: Heidelberg.

Pellman, E.J., Viano, D.C., Tucker, A.M., Casson, I.R., and Waeckerle, J.F. (2003). Concussion in professional football: reconstruction of game impacts and injuries. Neurosurgery 53, 799-812.

Pudenz, R.H., and Sheldon, C.H. (1946). The lucite calvarium-a method for direct observation of the brain. II. Cranial trauma and brain movement. J. Neurosurg. 3, 487-505.

Reilly, P.L., and Bullock, R. (eds). (2005). Head InjuryPathophysiology and Management, 2nd ed. Hodder Arnold: London.

Runnerstam, M., Bao, F., Huang, Y.-L., Shi, J., Gutierrez, E., Hamberger, A., Hansson, H.-A., Viano, D., and Haglid, K. (2001). A new model for diffuse brain injury by rotational acceleration: II. Effects on extracellular glutamate, intracranial pressure and neuronal apoptosis. J. Neurotrauma 18, 259-273.

Sabet, A.A., Christoforou, E., Zatlin, B., Genin, G.M., and Bayly, P.V. (2008). Deformation of the human brain induced by mild angular head acceleration. J. Biomechanics 41, 307-315.

Säljö, A., Bao, F., Haglid, K.G., and Hansson, H.-A. (2000). Blast exposure causes redistribution of phosphorylated neurofilament subunits in neurons of the adult rat brain. J. Neurotrauma 17, 719-726.

Shek, J.W., Wen, G.Y., and Wisniewski, H.M. (1986). Atlas of the Rabbit Brain and Spinal Cord. Karger: Basel.

Smith, D.H., and Meaney, D.F. (2000). Axonal damage in traumatic brain injury. Neuroscientist 6, 483-495.

Smith, D.H., Chen, X.-H., Xu, B.-N., McIntosh, T.K., Gennarelli, T.A., and Meaney, D.F. (1997). Characterization of diffuse axonal pathology and selective hippocampal damage following inertial brain trauma in the pig. J. Neuropathol. Exp. Neurol. 56, 822-834.

Stone, J.R., Okonkwo, D.O., Dialo, A.O., Rubin, D.G., Mutlu, L.K., Povlishock, J.T., and Helm, G.A. (2004). Impaired axonal transport and altered axolemmal permeability occur in distinct populations of damaged axons following traumatic brain injury. Exp. Neurol. 190, 59-69.

Suneson, A., Hansson, H.-A., and Seeman, T. (1990). Pressure wave injuries to the nervous system caused by high-energy missile extremity impact. Part II. Distant effects on the central nervous system: a light and electron microscopic study in pigs. I. Trauma 30, 295-306.

Zhu, H., Dahlström, A., and Hansson, H.-A. (2005). Characterization of cell proliferation in the adult dentate under normal conditions and after kainate induced seizures using ribonucleotide reductase and BrdU. Brain Res. 1036, 7-17.

Zhu, H., Wang, Z.-Y., and Hansson, H.-A. (2003). Visualization of proliferating cells in the adult mammalian brain with the aid of ribonucleotide reductase. Brain Res. 977, 180-189.

Address correspondence to: Hans-Arne Hansson, Ph.D. Institute of Biomedicine University of Gothenburg P.O. Box 440

SE 40530 Göteborg, Sweden

E-mail: hans-arne.hansson@gu.se 